\title{
IMAGING DIFFERENTIATION OF MALIGNANT HEPATIC TUMORS: RADIOMICS AND METABOLIC FEATURES OF 18F-FDG PET/CT
}

\author{
Mahmoud M.A. ${ }^{1}$, Shihab M. ${ }^{2}$, Saad SS. ${ }^{2}$, Elhussiny F.2, Houseni M. ${ }^{1}$ \\ 1 - Department of Radiology, National Liver Institute, Menoufia University. Shibin El-Koum, Egypt. \\ 2 - Department of Physics, Faculty of science, Tanta University. Tanta, Egypt.
}

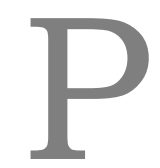

urpose. Different types of malignant hepatic lesions are difficult to diagnosis through imaging modalities depending on visual assessment. To study the potential of metabolic and radiomics parameters of $18 \mathrm{~F}$-fluorodeoxyglucose-positron emission tomography/computed tomography (FDG-PET/CT) in the classification of malignant hepatic lesions including hepatocellular carcinoma (HCC) and liver metastasis (LM) and cholangiocarcinoma (CC).

Materials and methods. Thirty-three primary tumors from 33 patients with HCC, 34 lesions of LM from 15 patients, and13 lesions of cholangiocarcinoma from 9 patients were included in this study. The lesions have been segmented from the PET images after the CT correction, then 7 metabolic features, 2 shape indices feature, and 35 radiomics features were extracted from images through semiautomatic method in LIFEx package. Kruskal-Wallis test was used to determine the significant different features. Finally, the area under the curve (AUC) was calculated to find the features with high sensitivity to characterize the tumor types.

Results. According to Kruskal-Wallistest, 4 metabolic parameters, 1 shape indices features, and 22 radiomics features were significantly different among tumor types. The most differentiating radiomics and metabolic features were GLRLM-GLNU and shape compactiy. Most of the features show high sensitivity to distinguish (HCC/LM) and (HCC/CC) according to the area under the curve (AUC).

Conclusions. Radiomics features in addition to metabolic parameters and shape indices from FDG-PET/CT studies may be of value in characterizing different malignant hepatic tumors.

Keywords: FDG PET/CT, liver, radiomics, metabolic parameters.

Corresponding author: Menna Allah Mahmoud, e-mail: m.shehata@liver.menofia.edu.eg

For citation: Mahmoud M.A., Shihab M., Saad SS., Elhussiny F., Houseni M. Imaging differentiation of malignant hepatic tumors: radiomics and metabolic features of 18F-FDG PET/CT. REJR 2021; 11(2):165-170. DOI: 10.21569/2222-7415-2021-11-2-165-170.

Received: $\quad 08.03 .21 \quad$ Accepted: 12.05 .21

\section{АИФФЕРЕНЦИАЛЬНАЯ АИАГНОСТИКА ЗАОКАЧЕСТВЕННЫХ ОПУХОАЕЙ ПЕЧЕНИ: ОСОБЕННОСТИ РААИОМИКИ И МЕТАБОАИЗМА 18F-ФАГ ПЭТ/КТ}

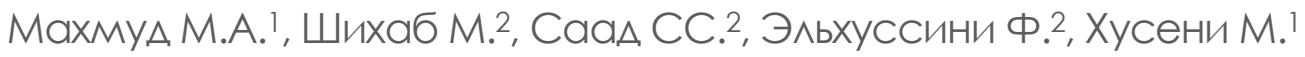 \\ 1 - Отделение мучевой диагностики. Национальный институт печени Университета Менуфия. \\ г. Шебин-Эмь-Кум, Египет. \\ 2 - Факультет физики, факультет естественньх наук. Университет Танта. г. Танта, Египет.
}

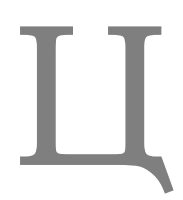

ель исследования. Разцичные типы зцокачественных поражений печени трудно диагностировать с помощью методов визуализации, основываясь только на визуальных характеристиках. Изучить потенциал метаболических и радиомических параметров 18F-фртордезоксиглюкозо-позитронно-эмиссионной томографии/компьютерной томо- 


\section{RUSSIAN ELECTRONIC JOURNAL OF RADIOLOGY}

графии (ФДГ-ПЭТ/КТ) в классификации змокачественных поражений печени, вклю-

чая гепатоцем^юлярную карциному (ГЦК) и метастазы в печень (МП), а также холангиокарциному (XK).

Материалы и методы. В исследование были включены тридцать три первичные опухоли у 33 пациентов с ГЦК, 34 поражения МП у 15 пациентов и 13 поражений по типу холангиокарциномы у 9 пациентов. Очаги поражения были сегментированы по ПЭТ-изображениям после КТ-коррекции, затем проведена оценка 7 метаболических признаков, 2 показателей формы и 35 радиомических признаков на изображениях полуавтоматическим методом в пакете LIFEx. Тест Крускала-Уомлиса использовался дмя определения значимых различий признаков. Пцощадь под кривой (AUC) была рассчитана для нахождения признаков с высокой чувствительностью, характеризующих типы опухолей.

Результаты. По данным теста Крускала-Уомииса, 4 метаболических параметра, 1 характеристика показателей формы и 22 радиомических признака достоверно различались с учетом типа опухолей. Наиболее значимыми признаками радиомики и метаболическими особенностями были GLRLM-GLNU и shape compacity. Большинство признаков показывают высокую чувствительность к различиям (HCC/LM) и $(\mathrm{HCC} / \mathrm{CC})$ в зависимости от площади под кривой (AUC).

Выводы. Особенности радиомики вместе с метаболическими параметрами и индексом формы на основании ФДГ-ПЭТ/КТ могут иметь значение при характеристике различных змокачественных опухомей печени.

КАючевые слова: ФДГ ПЭТ/КТ, печень, радиомика, метаболические параметры.

Контактный автор: Махмуд М.A., e-mail: m.shehata@liver.menofia.edu.eg

Для иитирования: Махмуд М.А., Шихаб М., Саад СС., Эльхуссини Ф., Хусени М. Дифференииальная диагностика злокачественных опухолей печени: особенности радиомики и метаболизма 18F-ФДГ ПЭТ/KT. REJR 2021; 11 (2):165-170. DOI: 10.21569/2222-7415-2021-11-2-165-170.

Статья получена: $\quad$ 08.03.21 $\quad$ Статья принята: $\quad$ 12.05.21

\section{I} ntroduction.

Liver cancer consider to be one of the most fatal cancers types worldwide, it may be primary or secondary, the most known primary types are hepatocellular carcinoma (HCC) accounting $70 \%[17]$ and Cholangiocarcinoma (CC) which is the second most known liver primary malignancies with approximately $10 \%-25 \%$ of all hepatic malignancies[33].

Secondary liver cancers including tumors metastatic to the liver are more known than primary cancers. The most common sites of the primary tumors are breast, lung, and colorectal cancer[1].

Accurate diagnosis of liver cancer is sometimes a hard process especially between HCC and ICC through biomarkers and radiological scans [18],[27].

Liver imaging is also done in patients with a history of cancer as the liver is the most frequently concerned organ by metastases. liver-imaging including ultrasonography (US), computed tomography (CT), magnetic resonance imaging (MRI), and positron emission tomography (PET) ought to incorporate liver lesion characterization as a necessary goal[20].
FDG-PET may detect liver masses with good power in these parathion of benign from malignant lesions and can be used to distinguish various liver masses, although certain lesions may be difficult to diagnose correctly $(7,8,9,10)$.

Radiomics is a new branch that depends on extracting extra data from medical images using advanced quantitative techniques such as texture analysis to enhance cancer diagnosis, treatment planning, and assessment [13]. Recently, radiomics through Various modalities have shown a good impact in liver cancer studies, and some authors use radiomics to characterize different liver cancers:

Zhang et al. (2020) used CT radiomics to differentiate combined hepatocellular and cholangiocarcinoma $(\mathrm{CHC})$ from intrahepatic cholangiocarcinoma (ICC) [32]. Li et al. (2017) studied radiomics through MRI to classify hepatic hemangioma $(\mathrm{HH})$, hepatic metastases (HM), and hepatocellular carcinoma (HCC)[15].

Raman et al. (2015) used Computed tomography texture analysis (CTTA) to classify cases of focal nodular hyperplasia, hepatic adenomas, hepatocellular carcinomas, and cases of normal liver parenchyma using arterial phase scans(13). 


\section{RUSSIAN ELECTRONIC JOURNAL OF RADIOLOGY}

Duda et al. (2006) used texture analysis on CT to classify normal liver tissue from HCC and Cholangiocarcinoma [6]. Yoshida et al. (2003) used ultrasound (US) texture analysis to distinguish benign (hemangiomas) from malignant (hepatocellular carcinomas (HCCs) and metastases) focal liver lesions in B-mode ultrasound images[30].

According to our knowledge, this is the first time to differentiate liver tumors using a PET scan. So, the current work aims to use $18 \mathrm{~F}$ FDG-PET/CT radiomics and metabolic parameters to characterize different liver tumors types.

\section{Materials and methods.}

Patients.

Thirty-three primary tumors from 33 patients with HCC with (29 males and 4 females with main age $=57.76), 34$ lesions of LM from 15 patients $(6$ females with breast cancer 3 females and 6 males with colon cancer, with main age = 56.4) and 13 lesions of cholangiocarcinoma from 9 patients ( 5 males and 4 females, main age $=54.08$ ) were included. Patients were referred to our department primarily to investigate the extra-hepatic disease before starting an adequate management plan. The hepatic lesions were diagnosed by histopathology. The study was approved by the institutional review board (IRB), and informed consent was waived.

The PET-CT scans for all patients have occurred at our Institute between January 2016 and April 2018.

\section{Imaging facilities.}

The study was carried out using a PET/CT scanner (Siemens Biograph 128_mCT, Germany). Patients were situated in the PET/CT scanner up to 60 minutes after intravenous injection of FDG. The FDG dose was measured by $0.1 \mathrm{mCi}$ or 3.7 $\mathrm{MBq}$ for each $\mathrm{Kg}$ based on their weight. A noncontrast CT scan was obtained from the base of the skull to the upper thigh and was used for attenuation correction. The size of the images was 200x200 pixels and the thickness of the slice was $1 \mathrm{~mm}$.

\section{Imaging processing and analysis.}

Lesions have been segmented from PET scans after CT correction using three- dimensional (3D) semiautomatic process after that thirty-five radiomics parameters, eight metabolic parameters, and two shape indices parameters were obtained using texture analysis of PET images using LIFEx software version 4.0.0 (https://www.lifexsoft.org/) [19]. Imaging interpretation and analysis were performed and revised by a qualified radiologist with experience in reading PET/CT for 15 years. Fig. 1 shows the workflow of feature extraction in this study.

Metabolic features.

Metabolic parameters were extracted depending on the standardized uptake value (SUV) which is defined as the tissue concentration of tracer as measured by a PET scanner divided by the activity injected and the body weight [11]. Many parameters related to SUV have been used in this study.

SUVmax.

Defined as maximum value of SUV in the area of interest, which is the commonly used SUV clinically.

\section{SUV mean.}

The mean SUV value in the area of interest. SUVmin. terest.

The minimum SUV value in the region of in-

SUVstd.

The standard deviation of SUVin the region of interest.

Metabolic tumor volume (MTV).

Measures the active volume in $\mathrm{ml}$

Total Lesion Glycolysis (TLG).

The product of SUV mean and MTV [14].

SUVpeak.

Reflects the SUV in a sphere with a volume of $1 \mathrm{~mL}$ and is located so that the average value in the volume of interest is maximum.

Intra tumor heterogeneity SUV(std/mean).

Using the coefficient of variation (COV), defined as the ratio between the standard deviation of SUV values and the mean SUV value within the delineated MTV value, the 18F-FDG uptake heterogeneity was estimated [8].

Shape indices features.

Sphericity and Compacity measure how spherical or compact a Volume of Interest, respectively.

\section{Radiomics features.}

Thirty-five radiomics features are studied. Histogram indices derived after determination of bin width, the gray level co-occurrence matrix (GLCM) takes under consideration the arrangements of pairs of voxels to calculate textural indices, the neighborhood gray-level different matrix (NGLDM) corresponds to the distinction of graylevel between one voxel and its twenty-six neighbors in three dimensions. The gray-level run length matrix (GLRLM) provides the scale of consistent runs for every gray-level. The gray-level zone length matrix (GLZLM) provides data on the scale of consistent zones for every gray-level in three dimensions. More details about the radiomics features used in this study can be found at:

(https://lifexsoft.org/index.php/resources/

19-texture/radiomicfeatures?filter_tag [0]=)

Statistical analysis.

Kruskal-Wallis test was used to obtain the difference between the features included in this study through the three cancer groups in 3D mode. AUC (area under the curve) was obtained from ROC (Receiver Operating Characteristics) 


\section{RUSSIAN ELECTRONIC JOURNAL OF RADIOLOGY}

curve for the significant parameters. The significance value for the tests was 0.05. The tests operated using IBM-SPSS Statistics package (version 19, SPSS Inc., Chicago, IL, USA).

\section{Results.}

Kruskal-Wallis test was applied to the features of the three groups as shown in table 1 . Regarding the metabolic parameters, 8 features were extracted from PET tumors images and 3 of them were statistically significantly different among the three groups, including SUVmin with $\mathrm{H}=29.8$ and $\mathrm{p}<0.0001$, TLG 25.8 and $\mathrm{p}<0.0001$ and MTV $\mathrm{H}=12.51$ and $\mathrm{p}<0.002$.

Regarding radiomics features, 22 features from a total of 35 were statistically different, the highest was gray-level non-uniformity for the run (GLRLM_GLNU) with $\mathrm{H}=36.62$ and $\mathrm{p}$ $<0.0001$.From the two shape indices parameters, compacity was highly statistically significant with $\mathrm{H}$ value $=34.54$ and $\mathrm{p}<0.0001$ while sphericity was statistically stable through the 3 groups.

The area under the curve (AUC) was derived from the receiver of characteristics (ROC) curve for the features with significant difference to obtain features that can distinguish between types of cancer, as shown in table 2. Most features were sensitive to classify HCC from LM and HCC from CC but no feature can differentiate between LM and CC. The highest significant radiomics features were GLRLM_GLNU with AUC $=0.92(95 \%$ CI: 0.87-0.98), 0.83(95\%CI:0.7-0.96) in HCC/LM and (HCC/CC) respectively and NGLDM-Busyness with $\mathrm{AUC}=0.86(95 \% \mathrm{CI}: 0.77-0.95)$ in case of $(\mathrm{HCC} / \mathrm{CC})$ and $\mathrm{AUC}=0.86(95 \% \mathrm{CI}: 0.74-0.9)$ in case of (HCC/LM).

Where all features could not differentiate (LM/CC) accurately, most of the features have AUC less than 0.6.

\section{Discussion.}

Radiomics may differentiate benign from malignant tumors and can identify primary from secondary cancer in cases with lung [12],[28],[3], brain [31], and breast[10] cancers.

According to the Kruskal-Wallis test, there were 3 metabolic parameters, 22 radiomics features, and one shape indices, with significant differences among different malignant hepatic tumor types. Fig 2,3,4 show display a PET scan for cases of HCC, liver metastasis, and cholangiocarcinoma respectively in $\mathrm{PET} 3 \mathrm{D}$ segmentation and fused images with significant values.Fig. 5 shows a box plot of the tumor types in shape compacity and GLRLM_GLNU. Furthermore, most of GLRLM and GLZLM features were significantly different.

From grey level co-occurrence matrix GLCM and histogram based features only correlation and kurtosis respectively were significantly different, Holli et al.(2010) found only MRI GLCM- features can differentiate breast cancer types using
MRI[10], Kreinko et al. (2018) found that histogram based feature scan differentiate histological stages and classify lesions as primary or metastatic, of lung cancer using PET scan [12].

To discover the ability of features to differentiate between each pair of tumors types, the area under the curve (AUC) was derived from the receiver of characteristics (ROC) curve. Most of the features show a high sensitivity to distinguish between (HCC/LM) and (HCC/CC).

Sarioglu1 et al.(2020) founded that GLRLM_GLNU and NGLDM-Busyness can differentiate pediatric craniofacial rhabdomyosarcoma (RMS) from infantile hemangioma (IH) in MRI images [25] . Palumbo et al. (2020) reported that SUV min, NGLDM-Busyness, and contrast can differentiate between benign and malignant solitary pulmonary nodules using PET images[22].Yang et al. (2019) founded that GLRLM_GLNU can classify mucinous cystadenoma and serous cystadenoma in CT images [29].

Our et al. (2018) reported that TLG and NGLDM_Contrast can distinguish between breast lymphoma and breast carcinoma in PET images with AUC higher than 0.7 [21] which agree with our findings.

In our study most features were sensitive to classify $\mathrm{HCC}$ from LM and HCC from CC. Duda et al. (2006) reported that first-order features, GLCM, GLRLM features can accurately classify $\mathrm{HCC}$ from $\mathrm{CC}$ and enhance diagnosis in different multiphase CT images[6]. Duda et al. (2013) reported that first order features, GLCM GLDM can classify $\mathrm{HCC}$ and $\mathrm{CC}$ from normal tissue and fibrosis[7]. Mala et al. (2007) used GLCM to classify $\mathrm{HCC}$ and $\mathrm{CC}$ with other liver cancer types in CT images [16].

Some authors reported using radiomics to classify between HCC and LM in different images phases of triphasic CT. Quatrehomme et al. (2013 ) used first order features [23]. Chei et al. (2013) used first order features, GLCM[4]. Where Li et al. (2017) used MRI to differentiate HCC and LM through GLCM and GLRLM [15].

\section{Study limitations.}

Limitations of our study may include the relatively small sample size especially in cholangiocarcinoma due its low incidence, and restricted number of features. Our research was taken from a single center and the extension of findings to the other centers would need to validate its reproducibility, which will be extended in our future works?

Another limitation is that the clinical courses of the disease and liver functions have not been compared with Radiomics. However, the focus of that investigation was to enhance the performance of FDG-PET/CT in classification various liver malignancies which gives promising results in this 


\section{RUSSIAN ELECTRONIC JOURNAL OF RADIOLOGY}

point as new tool to enhance liver cancer diagnosis.

\section{Conclusion.}

In conclusion, hepatocellular carcinoma, cholangiocarcinoma, and hepatic metastasis could

be differentiated by utilizing several radiomics fea-

\section{References:}

1. Ananthakrishnan A., Gogineni V., Saeian K. Epidemiology of Primary and Secondary Liver Cancers. Semin. Intervent. Radiol. 2006; 23 (1): 047-063.

2. Böhm B., Voth M., Geoghegan J., Hellfritzsch H., Petrovich A., Scheele J., Gottschild D. Impact of positron emission tomography on strategy in liver resection for primary and secondary liver tumors, 2004.

3. Chen C.H., Chang C.K., Tu C.Y., Liao W.C., Wu B.R., Chou K.T., Chiou Y.R., Yang S.N., Zhang G., Huang, T.C.: Radiomic features analysis in computed tomography images of lung nodule classification, (2018)

4. Chi Y., Zhou J., Venkatesh S.K., Tian Q., Liu J. Content-based image retrieval of multiphase $C T$ images for focal liver lesion characterization. Med. Phys, 2013. 40 (10).

5. Delbeke D., Martin W.H., Sandler M.P., Chapman W.C., Wright J.K., Pinson C.W. Evaluation of benign vs malignant hepatic lesions with positron emission tomography, 1998.

6. Duda D., Kretowski M., Bezy-Wendling J. Texture characterization for hepatic tumor recognition in multiphase CT. Biocybern. Biomed. Eng, 2006. 26 (4): 15.

7. Duda D., Kretowski M., Bézy-Wendling J. A computer-aided diagnosis of liver tumors based on multi-image texture analysis of contrast-enhanced CT. Selection of the most appropriate texture features. Stud. Logic, Gramm. Rhetor, 2013. 35 (48): 49-70. 8. Hatt M., Cheze-le Rest C., van Baardwijk A., Lambin P., Pradier O., Visvikis D. Impact of Tumor Size and Tracer Uptake Heterogeneity in 18F-FDG PET and CT Non-Small Cell Lung Cancer Tumor Delineation. J. Nucl. Med., 2011. 52 (11): 16901697.

9. He Y.X., Guo Q.Y. Clinical applications and advances of positron emission tomography with fluorine-18- fluorodeoxyglucose (18F-FDG) in the diagnosis of liver neoplasms, 2008.

10. Holli K., Lääperi A.L., Harrison L., Luukkaala T., Toivonen T., Ryymin P., Dastidar P., Soimakallio S., Eskola H. Characterization of Breast Cancer Types by Texture Analysis of Magnetic Resonance Images. Acad. Radiol, 2010. 17 (2): 135-141.

11.Keyes J.W. SUV: standard uptake or silly useless value? J. Nucl. Med, 1995. 36 (10): 1836-1839.

12. Kirienko, M., Cozzi, L., Rossi, A., Voulaz, E., Antunovic, L., Fogliata, A., Chiti, A., Sollini, M.: Ability of FDG PET and CT radiomics features to differentiate between primary and metastatic lung lesions. Eur. J. Nucl. Med. Mol. Imaging. 45 (10), 16491660 (2018)

13. Lambin P., Rios-velazquez E., Leijenaar R. Radiomics: Extracting more information from medical images using advanced feature analysis. Eur. J. Cancer. 2012. 48 (4): 441-446.

14. Larson S.M., Erdi Y., Akhurst T., Mazumdar M., Macapinlac H.A., Finn R.D., Casilla C., Fazzari M., Srivastava N., Yeung H.W.D., Humm J.L., Guillem J., Downey R., Karpeh M., Cohen A.E., Ginsberg R. Tumor treatment response based on visual tures, metabolic parameters, and shape compacity indecencies from FDG-PET/CT. The most sensitive radiomics feature is Gray-Level NonUniformity for run (GLRLM_GLNU). The most sensitive metabolic parameter are TLG, MTV and SUVmin.

and quantitative changes in global tumor glycolysis using PET$F D G$ imaging. The visual response score and the change in total lesion glycolysis. Clin. Positron Imaging, 1999. 2 (3):59-171.

15. Li Z. Mao Y., Huang W., Li H., Zhu J., Li W., Li B. Texturebased classification of different single liver lesion based on SPAIR T2W MRI images. BMC Med. Imaging, 2017. 17 (1).

16. Mala K., Sadasivam V. Automatic segmentation and classification of diffused liver diseases using wavelet based texture analysis and neural network. Proc. INDICON 2005 An Int. Conf. IEEE India Counc. 2005. 216-219.

17. Massarweh N.N., El-Serag H.B. Epidemiology of Hepatocellular Carcinoma and Intrahepatic Cholangiocarcinoma. Cancer Control, 2017. 24 (3): 1-11.

18. Murakami T., Tsurusaki M. Hypervascular benign and malignant liver tumors that require differentiation from hepatocellular carcinoma: Key points of imaging diagnosis, 2014.

19. Nioche C., Orlhac F., Boughdad S., Reuze S., Goya-Outi J., Robert C., Pellot-Barakat C., Soussan M., Frouin F. erique Buvat I. Lifex: A freeware for radiomic feature calculation in multimodality imaging to accelerate advances in the characterization of tumor heterogeneity. Cancer Res, 2018. 78 (16): 4786-4789.

20. Oliva M.R., Saini S. Liver cancer imaging: Role of CT, MRI, US and PET. Cancer Imaging, 2004. 4: 42-46.

21. Ou X., Wang J., Zhou R., Zhu S., Pang F., Zhou Y., Tian R., Ma X. Ability of 18 F-FDG PET/CT radiomic features to distinguish breast carcinoma from breast lymphoma. Contrast Media Mol. Imaging. 2019.

22. Palumbo B., Bianconi F., Palumbo I., Fravolini M.L., Minestrini M., Nuvoli S., Stazza M.L., Rondini M., Spanu A. Value of Shape and Texture Features from 18F-FDG PET/CT to Discriminate between Benign and Malignant Solitary Pulmonary Nodules: An Experimental Evaluation. Diagnostics, 2020. 10 (9): 696.

23. Quatrehomme A., Millet I., Hoa D., Subsol G., Puech W. Assessing the classification of liver focal lesions by using multiphase computer tomography scans. Lect. Notes Comput. Sci. (including Subser. Lect. Notes Artif. Intell. Lect. Notes Bioinformatics). 7723 LNCS 80-91.

24. Raman S.P., Schroeder J.L., Huang P., Chen Y., Coquia S.F., Kawamoto S., Fishman E.K. Preliminary Data Using Computed Tomography Texture Analysis for the Classification of Hypervascular Liver Lesions, http://www.ncbi.nlm.nih.gov/pubmed/25700222\%0Ahttp://co ntent.wkhealth.com/linkback/openurl?sid=WKPTLP:landingpag e\&an=00004728-900000000-99760, 2015.

25. Sarioglu F.C., Sarioglu O., Guleryuz H., Ozer E., Ince D., Olgun H.N. MRI-based texture analysis for differentiating pediatric craniofacial rhabdomyosarcoma from infantile hemangioma. Eur. Radiol. 2020. 30 (10): 5227-5236.

26. Tan G.J.S., Berlangieri S.U., Lee S.T., Scott A.M. FDG 


\section{RUSSIAN ELECTRONIC JOURNAL OF RADIOLOGY}

PET/CT in the liver: Lesions mimicking malignancies. Abdom. Imaging, 2014. 39 (1): 187-195.

27.Venkatesh S.K., Chandan V., Roberts L.R. Liver masses: A clinical, radiologic, and pathologic perspective. Clin. Gastroenterol. Hepatol, 2014. 12 (9): 1414-1429.

28. Wu W., Parmar C., Grossmann P., Quackenbush J., Lambin P., Bussink J., Mak R., Aerts H.J.W.L. Exploratory Study to Identify Radiomics Classifiers for Lung Cancer Histology. Front. Oncol, 2016. 1-11.

29. Yang J., Guo X., Zhang H., Zhang W., Song J., Xu H., Ma X. Differential diagnosis of pancreatic serous cystadenoma and mucinous cystadenoma: Utility of textural features in combination with morphological characteristics, 2019.

30. Yoshida H., Casalino D.D., Keserci B., Coskun A., Ozturk O.,
Savranlar A. Wavelet-packet-based texture analysis for differentiation between benign and malignant liver tumours in ultrasound images, 2003.

31. Zacharaki E.I., Wang S., Chawla S., Yoo D.S., Wolf R., Melhem E.R., Davatzikos C. Classification of brain tumor type and grade using MRI texture and shape in a machine learning scheme, 2009.

32. Zhang J., Huang Z., Cao L., Zhang Z., Wei Y., Zhang X., Song B. Differentiation combined hepatocellular and cholangiocarcinoma from intrahepatic cholangiocarcinoma based on radiomics machine learning. Ann. Transl. Med, 2020. 8 (4): 119-119.

33. Risk factors for cholangiocarcinoma. Tyson, 2011. Wiley Online Library. 